\title{
Meeting in the Ether: A Brief History of Virtual Worlds as a Medium for User-Created Events
}

Bruce Damer,

DigitalSpace Corporation, Santa Cruz, USA

\begin{abstract}
Virtual worlds, shared graphical spaces on the Internet, are an exciting new medium of human presence for the twenty-first century. This article explores the origins, evolution, and future of the virtual world medium from their humble beginnings in multi-player games to their use in education, business, science, and engineering. Its focus will be on the development of social virtual worlds including environments such as Habitat, Active Worlds, and Second Life.
\end{abstract}

Keywords: avatars, multi-user, virtual worlds, 3D environments

\section{PREAMBLE}

If the telephone, radio, film, and TV helped to defined life in the twentieth century, I propose that the virtual world is the one true new medium of the twenty-first. The virtual world was built on the shoulders of a true giant: the behemoth of interconnected computing spaces known as the Internet, and delivered through an uncountable number of processes and pixels onto billions of interactive computer screens. Interactive computing was brought forth by an insatiable appetite for game play, serious work, and now, social interaction.

While the virtual world combines aspects of the printed page, telegraph, telephone, film, radio, TV, and uses the World Wide Web as an access point, it is truly a unique experience that grew up separate from the document-centric Web. This article is dedicated to a brief exploration, and, as you will see, a rather personal accounting of the origins of this profound new medium and its use as a space where users create their own experiences, specifically user-driven meetings and events.

\section{WHAT IS A VIRTUAL WORLD?}

If we define the virtual world as a place described by words or projected through pictures which creates a space in the imagination real enough that you can feel you are inside of it then the painted caves of our ancestors, shadow puppetry, the seventeenth-century Lanterna Magica, a good book, theatre play, or movie are all technologies to create virtual worlds. The digital computer, a new tool eminently capable of dealing with words and pictures, was destined to become a purveyor of virtual worlds but with a new twist: the computer and the network in which it lives can host virtual worlds which are inhabited and co-created by people participating from different physical locations.

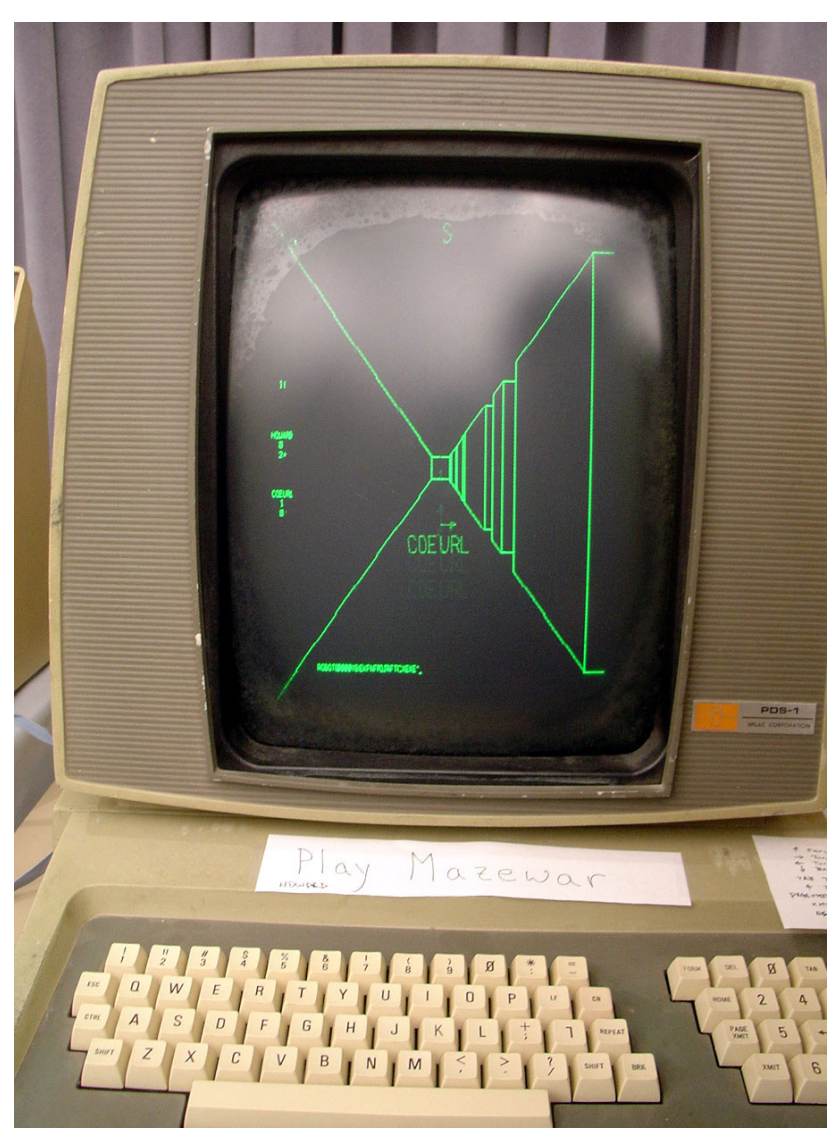

Figure 1. Maze War running on an early 1970s Imlac PDS-1, as featured in a 2004 DigiBarn Computer Museum restoration project. 


\section{THE ORIGINS OF VIRTUAL WORLDS IN DIGITAL COMPUTING AND NETWORKS}

Text-based role-playing games that operated on timesharing systems prefigured the explosion of imaginative word-built worlds of Adventure, Avatar, and other games on PLATO, the first MUDs (multiuser dungeons) and other online environments of the 1970s and 1980s. As the age of affordable graphical computing dawned in the mid-1980s, there was a natural instinct to create visual versions of these experiences (with the unintended forfeiture of the imaginative contribution of written language). The new-born medium of the graphical, digital virtual world experienced a "Cambrian Explosion" of diversity in the 1980s and 1990s, with offspring species of many genres: first-person shooters, fantasy role-playing games, simulators, shared board and game tables, and social virtual worlds.

\section{THE SOCIAL VIRTUAL WORLD}

Here we will focus on the last genre, social virtual worlds, in which the primary purpose is the creation of meaning through the manipulation of the world and communication with others within the world. Game-play worlds, while also supporting social interaction and user-created content, have as their primary purpose structured play. For the most part, in a social virtual world users are asked to "make it all up" for themselves.

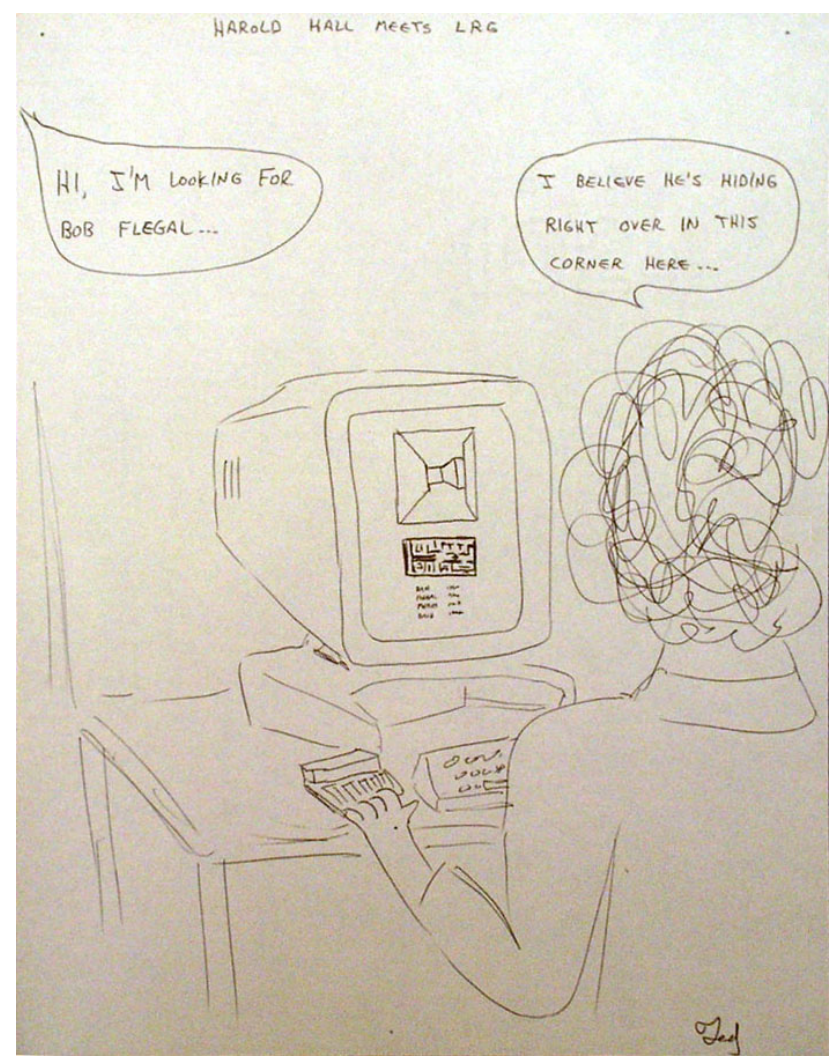

Figure 2. Maze War (Ted Kaehler, c.1980)

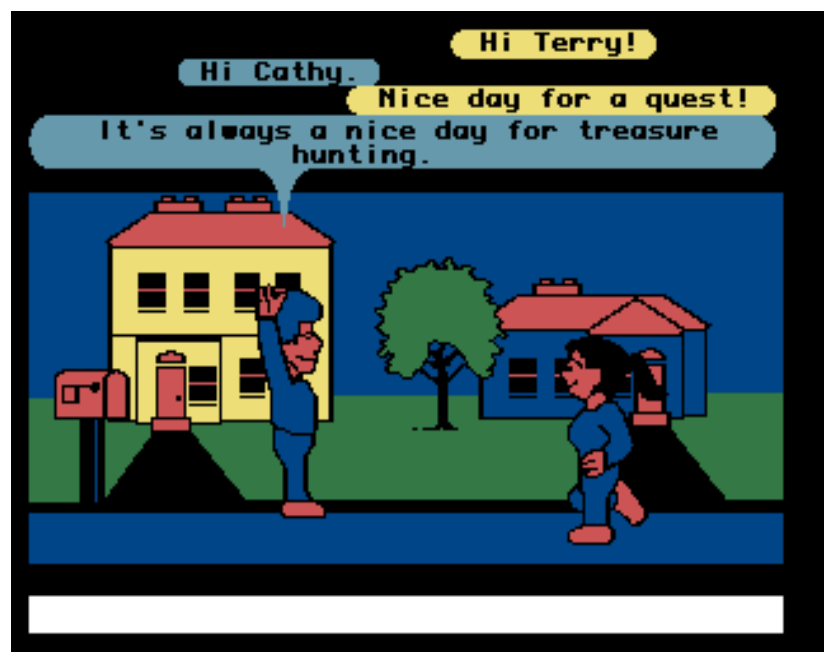

Figure 3. Habitat (1986).

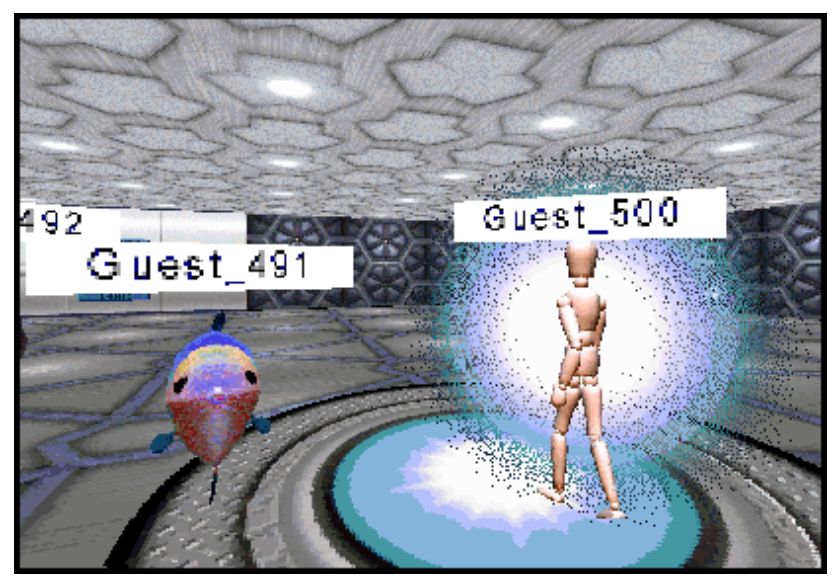

Figure 4. Worlds Chat(1995).

Maze War (Damer 1991), created first on two networked Imlacs PDS-1 vector graphics workstations (Figure 1) at NASA Ames Research Center in 1974, was the first software to fill the niche of the first-person shooter (users travelled around a 3D maze shooting at each other) but it also set the stage for the very concept of being "in-world" (a term that I coined in 1995 to describe the act of being, well, "in a world"). The cartoon drawn by Ted Kaehler around 1980 (Figure 2) shows a player of the Alto version of Maze being asked " $\mathrm{Hi}$, I'm looking for Bob Flegal..." and being told "I believe he's hiding right over in this corner here ..." (i.e. inworld rather than simply down the hall). Maze also created many of the innovations that would later come to define the virtual world's medium: instant messaging, non-player robot characters, levels, and in-world building. Players would often simply use Maze to have a chat. Maze also created the online interaction dichotomy between static documents and dynamic interaction still present today in the relatively static document Internet of the World 
Wide Web versus the dynamic inhabited Internet of chatrooms, shared video and audio, multi-player games, and virtual worlds.

Imlacs or Altos were too large and expensive to leave the laboratory for lives in suburban homes, but with the arrival of affordable colourgraphics capable personal computers such as the Commodore 64, and low-speed dial-up network interfaces, the stage was set for the first graphical, social virtual world, Habitat (Morningstar 1991), created by Chip Morningstar and Randy Farmer working at Lucasfilm in the mid-1980s. The Habitat screen capture (Figure 3) shows users (for the first time referred to as "avatars") interacting through text chat and moving around a built environment that could change through time. Users bartered objects and eventually created self-government independent of the server operators - the social virtual world had arrived.

\section{THE FIRST GENERATION OF SOCIAL VIRTUAL WORLDS ON THE INTERNET}

As CPU and system performance increased through the early 1990s, it became possible to run realtime, textured 3D graphics on a consumer PC. In the spring of 1995, a company called Worlds Incorporated launched Worlds Chat, a 3D space station where users "teleported" in and could navigate in a rich sound and spatial experience and, of course, exchange text chat (Figure 4).

Three months later, the same company launched Alphaworld, an experimental platform to allow users to build in-world using prefabricated objects.
Alphaworld was a key proving ground of the social virtual worlds medium. My two organizations, the Contact Consortium and DigitalSpace, carried out several years of experiments, including group meetings and shared building in the earliest Alphaworld versions (ground zero gathering in summer 1995, Figure 5, left) all the way to a full cyber-conference with thousands of attendees (“Avatars98", Figure 5, right). Other important platforms of this period included WorldsAway (successor to Habitat), which expanded the realm of barter and an object economy, Onlive Traveler (which pioneered voice and lip-synching avatars for intimate social interaction), and The Palace (which allowed any Palace user to easily create and host his/her own 2D shared "room" utilizing a simple image backdrop, which catalysed a viral spread of distributed worlds). My book (Damer 1997) is a guide to this first generation of social virtual worlds on the Internet.

\section{ON THE ORIGINS OF THE TERM VIRTUAL WORLD}

An interesting footnote here is the origin of the term virtual world as applied to online multi-user graphical environments. In the mid-1990s it was not at all clear what to call these new spaces. Users of earlier text-based worlds referred to them as graphical MUDs, those familiar with immersive virtual reality used the term VR with a number of prefixes (online VR, net VR, web $V R$ ), whilst academics were coining their own less than memorable terms such as collaborative virtual environments (CVEs), multi-user virtual environments (MUVEs), and members of the press
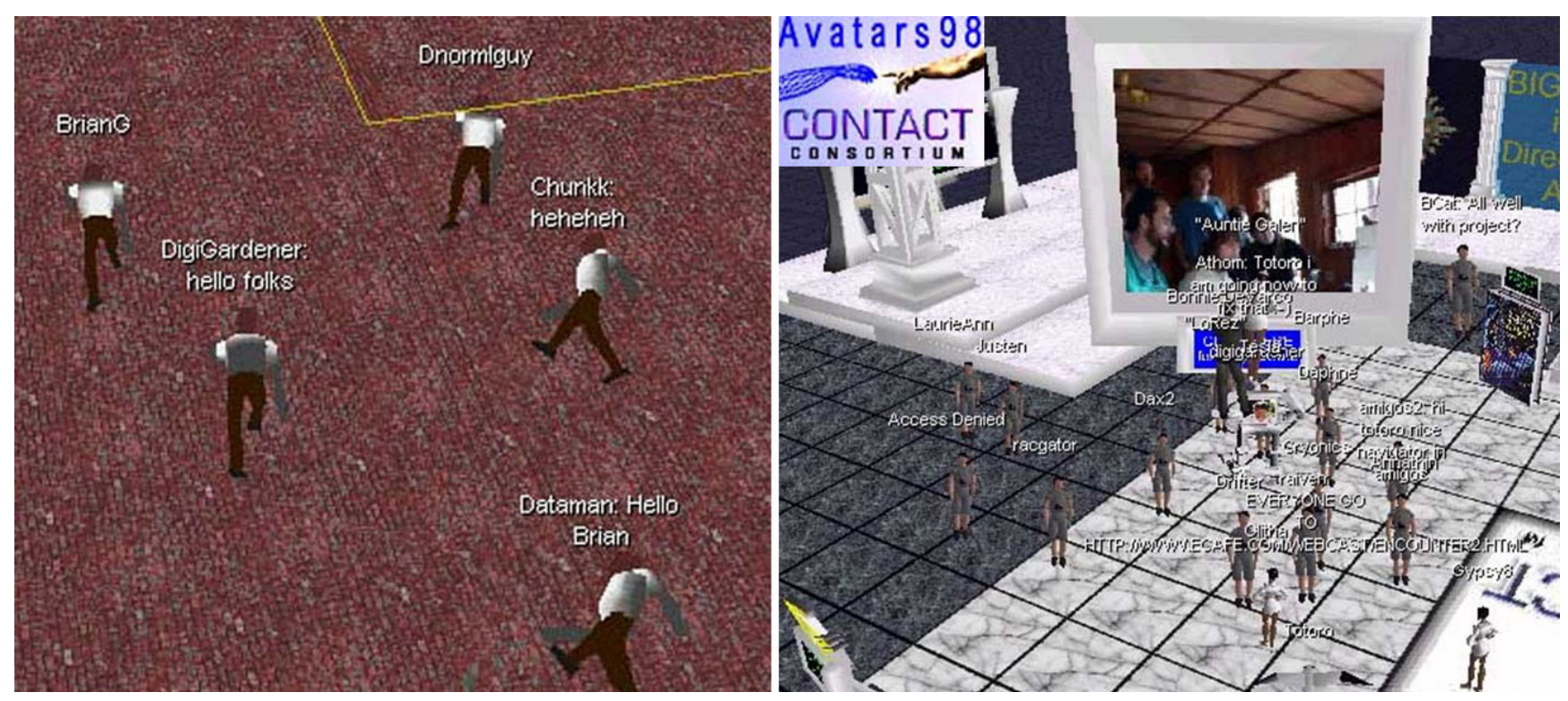

Figure 5. Alphaworld (1995 and 1998). 


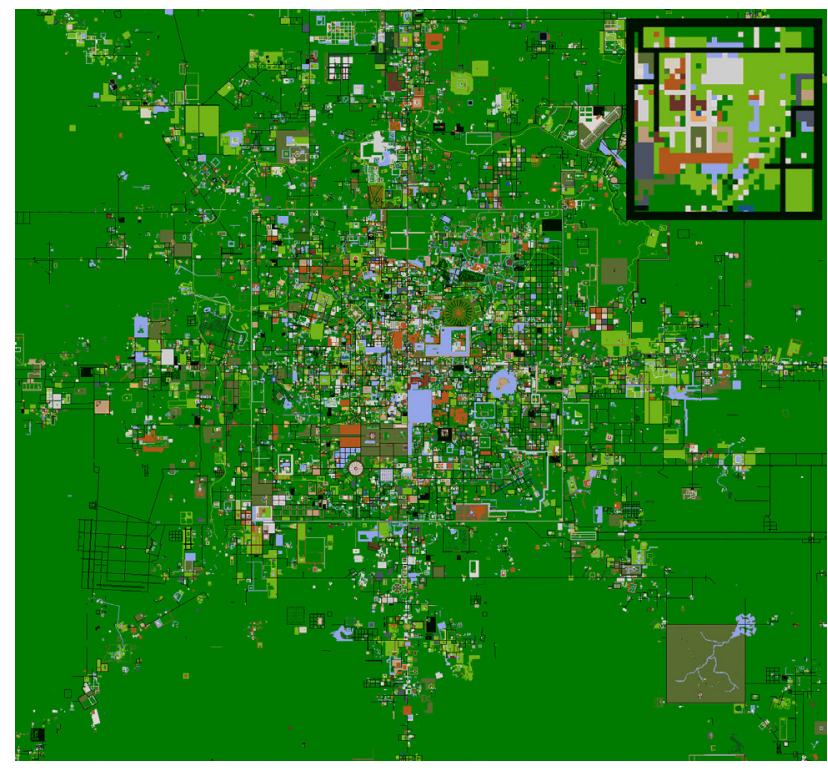

Figure 6. Alphaworld as "seen from space" at the end of 1996, Sherwood Forest Towne in inset.

and authors of key nonfiction books at the time had put forth terms such as the metaverse (Stephenson 1992) or mirror worlds.

At the time I proposed and continually promoted the term virtual world to distinguish the medium from earlier technologies. As the automobile was called a horseless carriage for a few years, it was time to give a new medium a proper name that would be both descriptive and flexible for future incarnations. I recall many a time when I would correct someone in-world (another term I believe I coined) saying "it's not VR, it's a virtual world". I also used the virtual world term in the subtitle of my book on avatars, in every speech and conference I hosted or participated in. While not perfect, the term virtual world has stuck and Chip Morningstar's term Avatar has survived along with it for more than two decades. Today the term virtual world is sometimes lumped in with multi-player gaming but to those in the inside, they know it is the distinct genre where users create the majority of the experience and meaning they come there to experience.

\section{MEETING IN THE ETHER: THE INVENTION OF LARGE SCALE EVENTS IN VIRTUAL WORLDS}

\section{The Contact Consortium}

The Contact Consortium, a not-for-profit organization based in Northern California, was founded in 1995 to serve as a community center and instigator of experimentation in the nascent medium of virtual worlds. The Consortium held two physical conferences in San Francisco ("Earth to Avatars" in 1996 and "Avatars 97") before deciding to move its event "inworld" and tried to hold a full-scale convention within the medium of virtual worlds in the fall of 1998. "Avatars98",

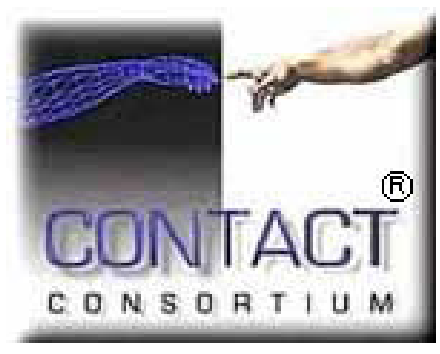
held for 4000 attendees dialing in over slow modem connections into a single shared 3D space, was a resounding success. Over the subsequent years, seven annual "cyber conferences" were held, each pushing the limits of design and experience of the virtual worlds medium as a space for gatherings, performance and presentations, art and personal expression. We will now take a closer look at the steps that led up to the holding of "Avatars98" and how the event was built, organized, and delivered to a pioneering avatar audience.

\section{First baby steps: Worlds Chat and Sherwood Forest Towne}

When Worlds Chat appeared online in May 1995 the Consortium membership tried it out as a cyber-gathering space. There were several "meeting rooms" but they were so much like bland windowless office conference rooms that users studiously avoided them, preferring the chaotic but social hub or scenic pods and viewpoints. Consortium members met with the group that produced Worlds Chat and pleaded for an environment where they could build their own content.

Our prayers were answered when Alphaworld came online two months later and allowed any user to build by simply picking and placing prebuilt objects (a concept that contributed to the

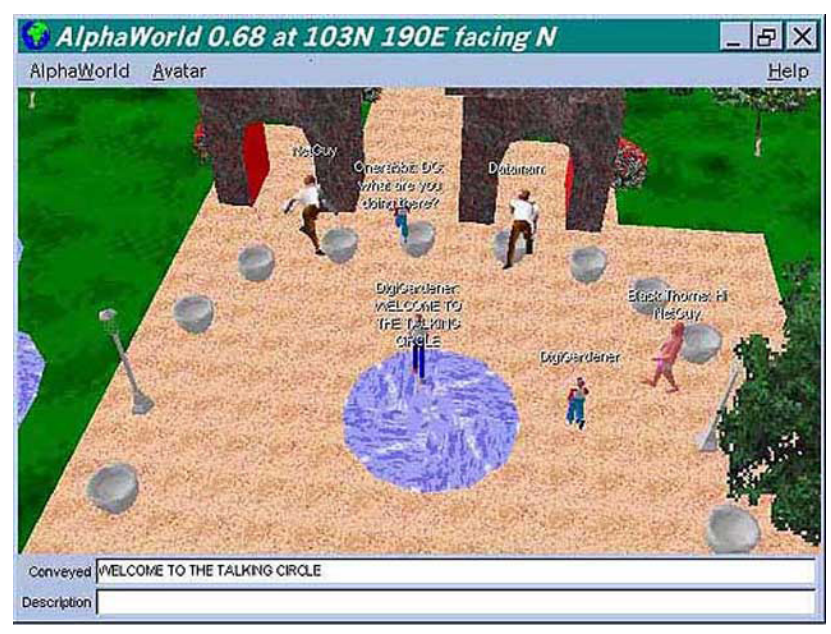

Figure 7. "Welcome to the Talking Circle" in Sherwood Forest Towne, Alphaworld, spring 1996, the first in-world experiment hosted by the Contact Consortium. 
Figure 8. Garden Party and Virtual Poetry Reading (Summer 1996)

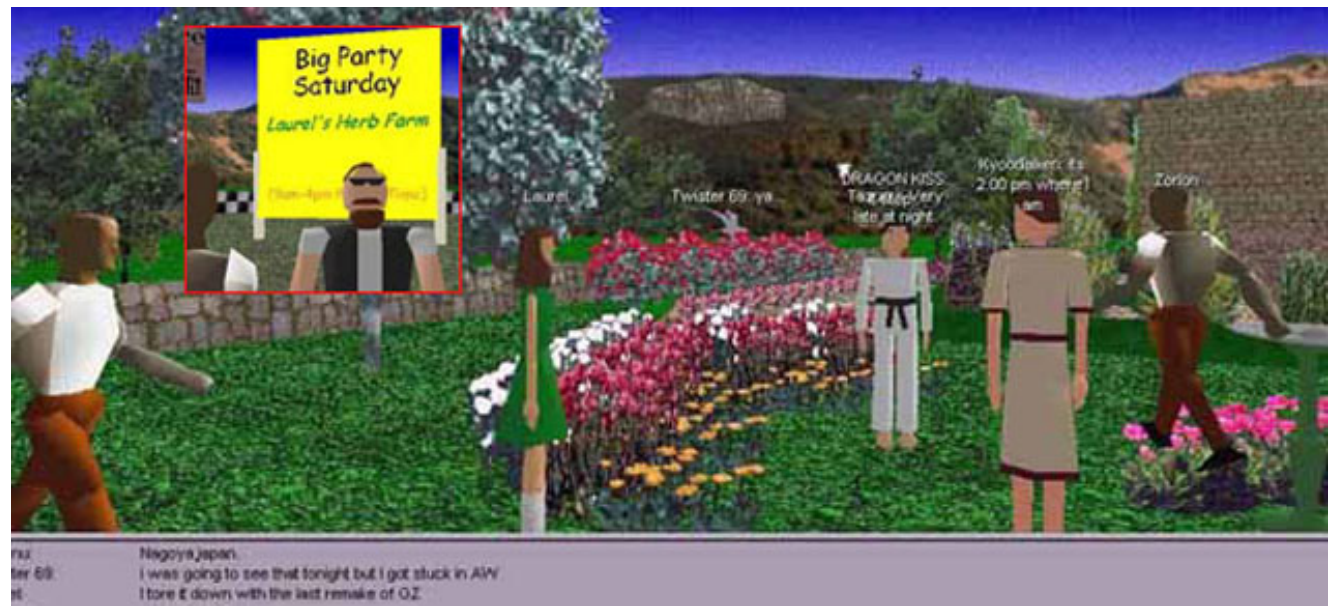

Figure 9. Heathrow Terminal 4 location where the design of the Avatars98 Cyberconference main hall was derived. success of Second Life years later). Figure 6 shows the explosion of construction in a viewpoint "from above" with our first project in the inset. With Alphaworld, the Consortium was then ready to carry out its first experiment: Sherwood Forest Towne.

Sherwood Forest Towne was our first attempt to recruit a team of builders to create a purposebuilt space in the "explosion of architecture" that
Alphaworld represented. We wanted to build a town to a plan with a theme (Olde English) and characters with roles (Robin Hood, a prankster, and so forth), and to create something small scale with structures close together, in contrast to the huge complexes typical of early Alphaworld builders. Sherwood was a fascinating first step for the organization and went on to win an award at the Austrian "Ars Electronica" conference in 1997. In Figure 7 you can see the purpose-built space we conceived to hold project meetings, the "Talking Circle". As Alphaworld allowed both a first person and third person "bird's-eye view" we used this second mode to be able to read the chat from every attendee's point of view. The pots provided a context and boundary and the central water pattern a point for the person "holding the talking stick". In early Alphaworld there was no separate chat window so this was the only way to guarantee that all shared the gates to Sherwood, was used frequently and led to a series of interesting experiments, including the first events, described next. the conversation. This primitive meeting space, at
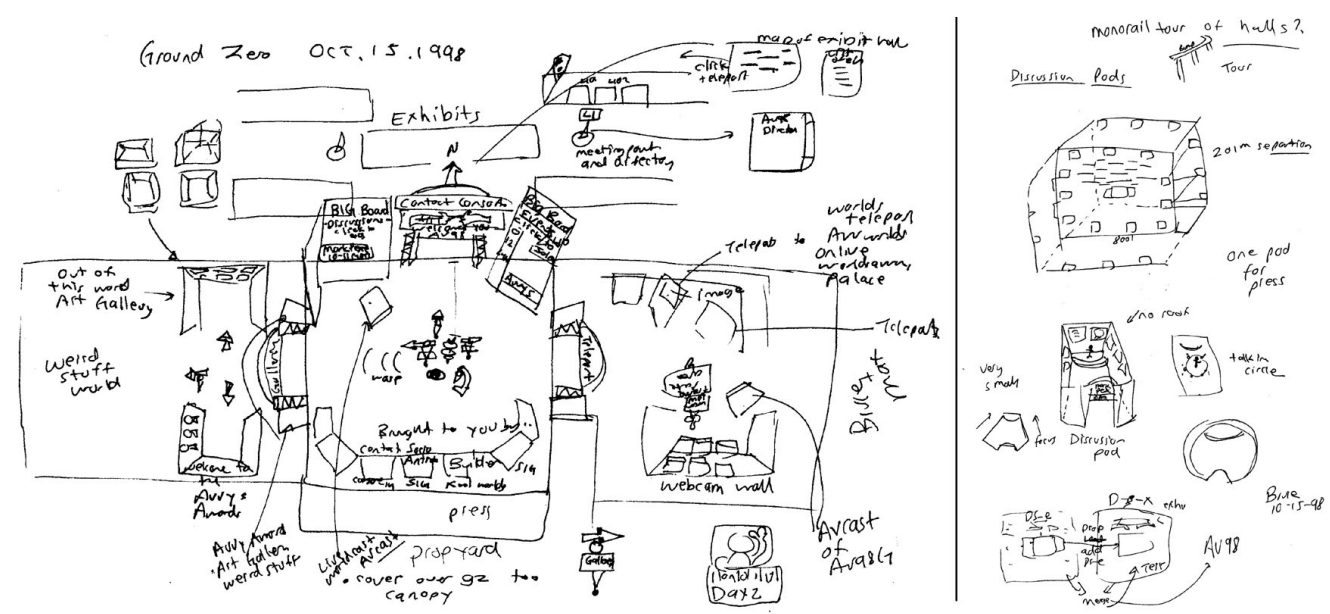

Figure 10. Design sketch for the "Avatars98": Inside Cyberspace event in 0ctober 1998, the first in-world conference hosted by the Contact Consortium. 


\section{Avatars 98}

OBJECTS (Functional)

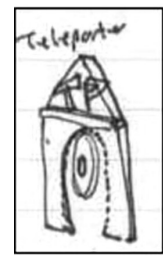

Teleporter

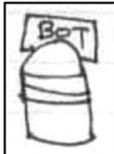

Bot
Email Stand

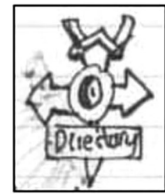

Directory Kiosk

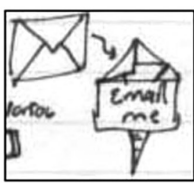

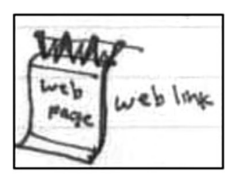

Web Stand

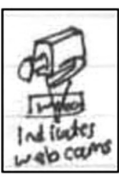

Webcam Stand
Figure 11. Drawings of original functional objects including teleporters, email link objects, directory kiosks etc

The first event, Mix it Up! Avatar Party in Digital Space (Figure 8), was held in July 1996 and featured a garden party in Sherwood Forest Towne, a firstever avatar poetry reading by noted Santa Cruz poet JJ Webb in a virtual redwood grove, and simultaneous bashes inside The Palace (a costume ball) and Black Sun's Pointworld. This gave us the confidence to hold more "in-world" events and set the stage for the Avatars Cyberconferences.
The Avatars Cyberconferences: a case study in productive play in virtual worlds

The Contact Consortium hosted its first conference, "Earth to Avatars", in October 1996, at a hotel in San Francisco, with over 500 attendees. Our second conference, "Avatars 97", held at San Francisco State University, Multimedia Studies Program, drew 400 attendees. We realized for the 1998 event that it was going to be difficult to find an affordable venue and that we were missing our constituency, the citizens of virtual world cyberspace, so we opted to "walk our talk" as an organization and move the event fully in-world. Hence "Avatars 98: Inside Cyberspace" was born.

On a trip to the UK to meet Consortium architect Stuart Gold (a real architect who moved his practice inside virtual worlds), we conceived of the design of the "Avatars98" conference space while sitting inside a Heathrow terminal building (Figure 9). We decided to create a large, open hall with areas to the north, south, east, and west of the "ground zero" landing area. Figure 10 below shows my design for these spaces as well as the "discussion pods" and exhibit hall booths that Stuart's database interface would automatically build for speakers and exhibitors.

Figure 11 show some of the detailed drawings of objects that would guide users in-world during Avatars98 in Active Worlds. The objects built

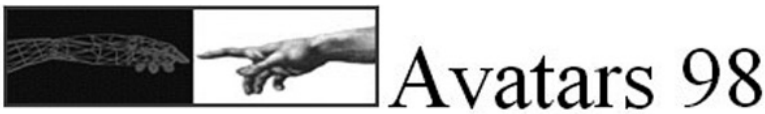

\section{OBJECTS (Medium Stand)}

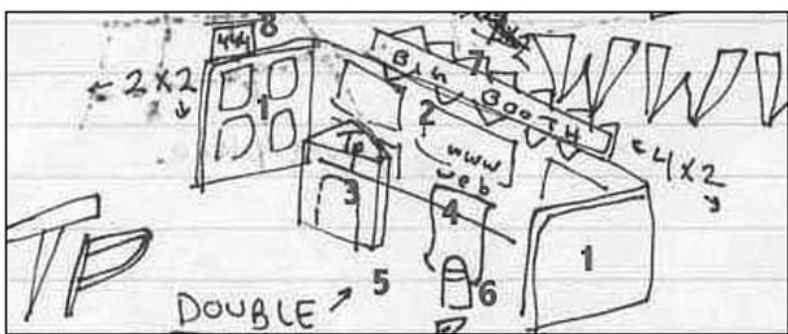

Object proposal: Stand Style 2
Figure 12. Detailed description of a medium sized "stand" (exhibit hall booth) for Avatars 98

1) This is the middle sized style stand, four units long with the following options:

- Placement of website URL behind an image or descriptive text on one of two rows of two end panels (1) or on one of four back panels (2x2) at (2)

- Inclusion of a teleporter to another AW world or other world accessible by web teleport (3) This teleporter could also take the visitor to an ongoing discussion area in an assigned pod.

- A webstand link (4) which is a more prominent link to a website, which will come up either as a separate web browser when clicked or will come up as a browser within a frame of the world browser (if IE 3.0 or higher is installed).

- A live embodied exhibit host as an avatar (5) either full time or during posted times.

- A bot (6) with defined behavior to greet and direct visitors to the exhibit.

- An exhibitor's signage, one or two lines deep, in a standard style of frame (7)

- A booth number (8) 
were reasonably close to the original conception. Interestingly the entire sketch (including all objects) for the Avatars98 event was done on the flight from London Heathrow to San Francisco.

Functional parts were detailed on this snap shot from the original Avatars98 instructional web site (Figure 12). The exhibit hall booths were created by database, permitting users to log into a web form, specify the size of booth, objects, images, clickable web references (URLs), and placement. The entire exhibit hall was thus autogenerated by a Delphi database and bots within the Active Worlds world. The technology was provided by Alex Grigny de Castro's "Xelagots" platform. The ease of use of the web form and automatic generation we felt was a good model for future virtual worlds platforms. There is no need to subject many users of virtual worlds to the rigors of building when it could be specified using more familiar metaphors (web forms, documents, and databases) and automatically created. We felt that automatic generation of other services such as bots for transcription, announcements, animations and text-chat monitoring (for evicting miscreant attendees) would also come in the future. Avatars 99 and subsequent events gave us a chance to try out this kind of functionality.

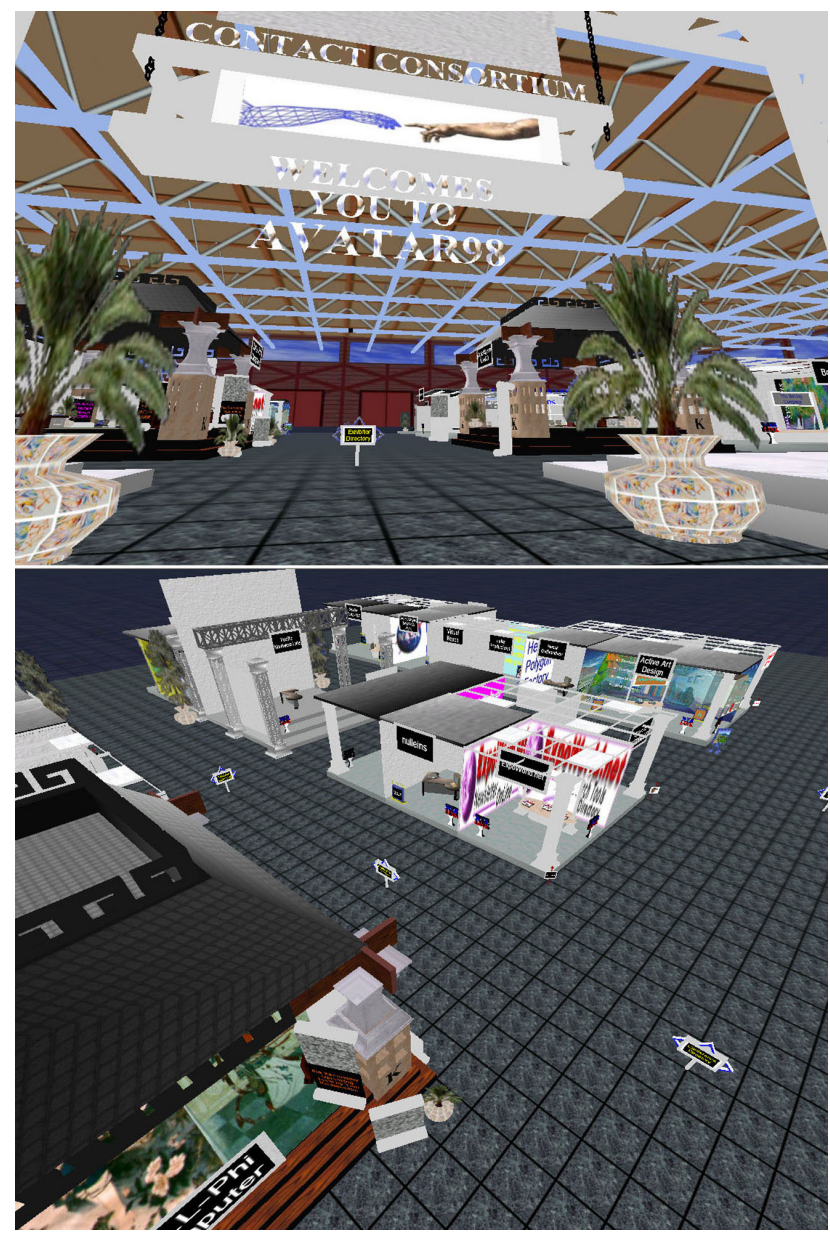

Figure 13. "Avatars98" Exhibit hall booths, all assembled from parts via a web-based database.

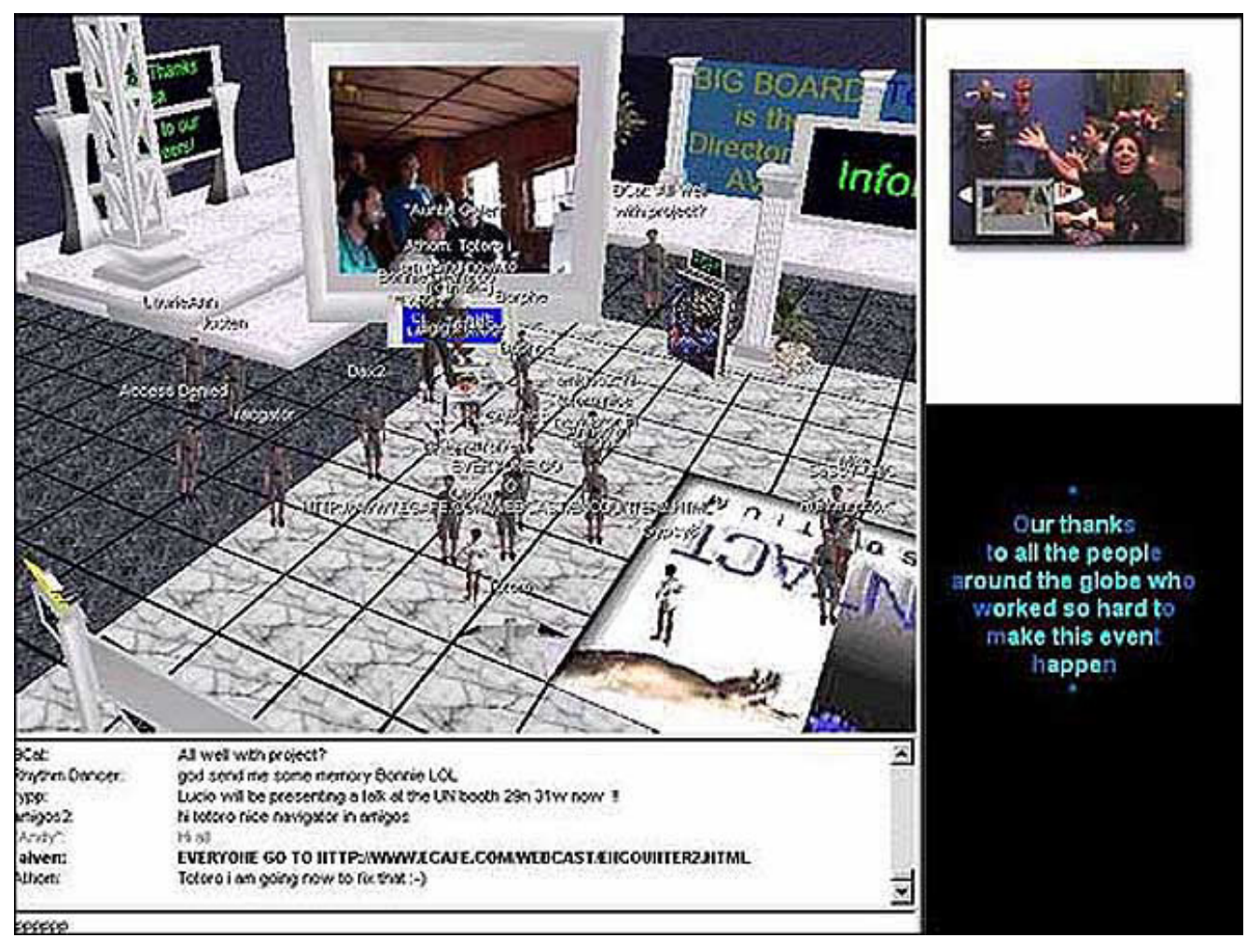

Figure 14. "Avatars98" Ground Zero as the conference opened, note the webcam in the web interface to the right broadcast from the Electronic Cafe in Santa Monica, California, and the webcam on a screen in-world broadcast from Ancient Oaks Farm in Northern California. 
Avatars98 also had parallel events in other popular platforms of the day including Blaxxun, Traveler, The Palace and WorldsAway. However, our main efforts focused on the Active Worlds platform due to its flexibility in building and managing events.

The next month was packed with frantic activity as we recruited object modelers, built web interfaces, and assembled the Avatars98 staff and spaces. By sticking with a simple, well-understood metaphor of a single convention hall with exhibits in one direction, and the other activities in the other three, we felt we would guarantee attendees at least a cognitively simple landscape. Beyond that, we were loading up the event with more than any virtual world had carried before: dozens of booths all built by a web page/database and "bot" interface (Figure 13), a wall of multiple webcams showing

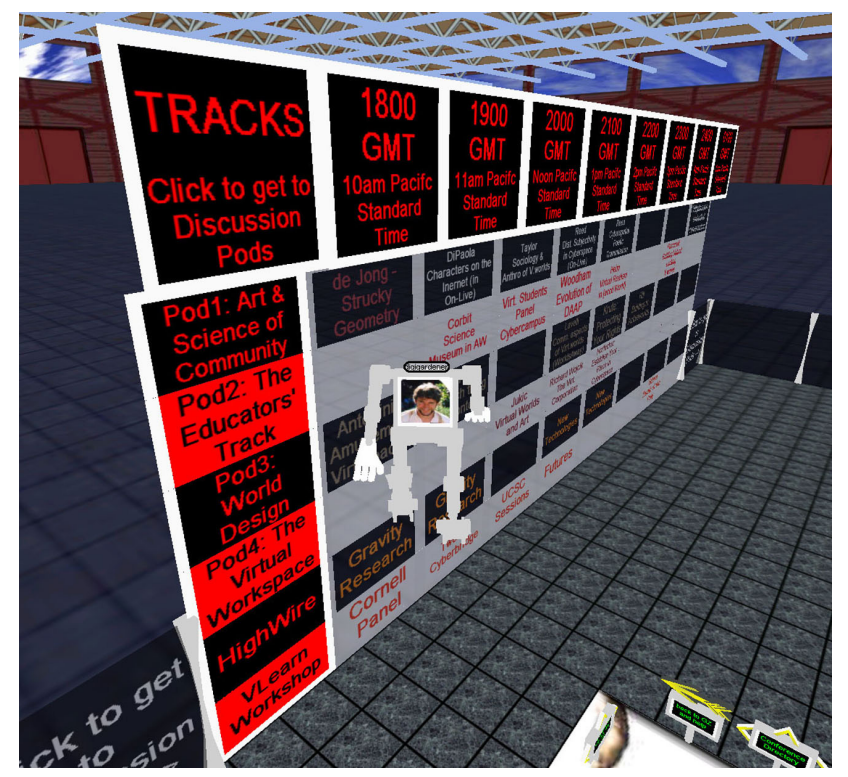

Figure 16. “Avatars98" Big Board, one click warped users to speaker pods throughout the hall.

different "nodes" or physical event sites around the globe, an art gallery and "Avvy Awards" stage with images of contest entries displayed by bot (an automated program inside the world). The event would also probably break attendance records for users entering a single avatar space running on one server. So how did it all turn out?

\section{Opening day}

Opening Day, November 21, 1998, was a tense moment. "Avatars98" had been featured the night before on CNN, which had brought a crush of additional users into the space. As this was in the era before broadband most of us were dialing in on modem connections on first- or second-generation

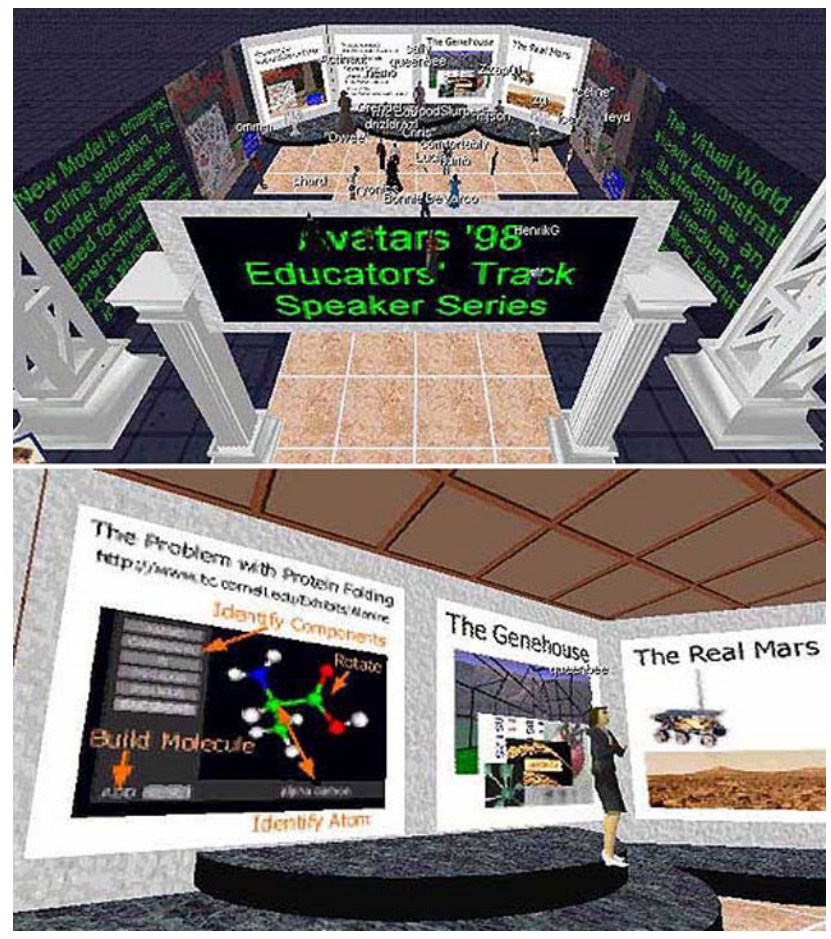

Figure 15. "Avatars98" Speaker pods for VLearn3D session. Pods built by database and slide images displayed by bot command.

Pentium machines. The entire event was run off a single Sun server hosted by the Active Worlds Company in Newburyport Massachusetts. The Consortium ran an event node and "jacking in" location from Ancient Oaks Farm in Boulder Creek, California. There were two-dozen other official "nodes" worldwide including the Electronic Cafe in Santa Monica, California (see Figure 14), Michael Nesmith's Video Ranch in New Mexico, and a big art museum in Helsinki, Finland. The event population started early in our morning time here in California to climb to well over 300 people in the single space. As the image in Figure 14 shows, the entry space got crowded and we had to use the "public speaker"

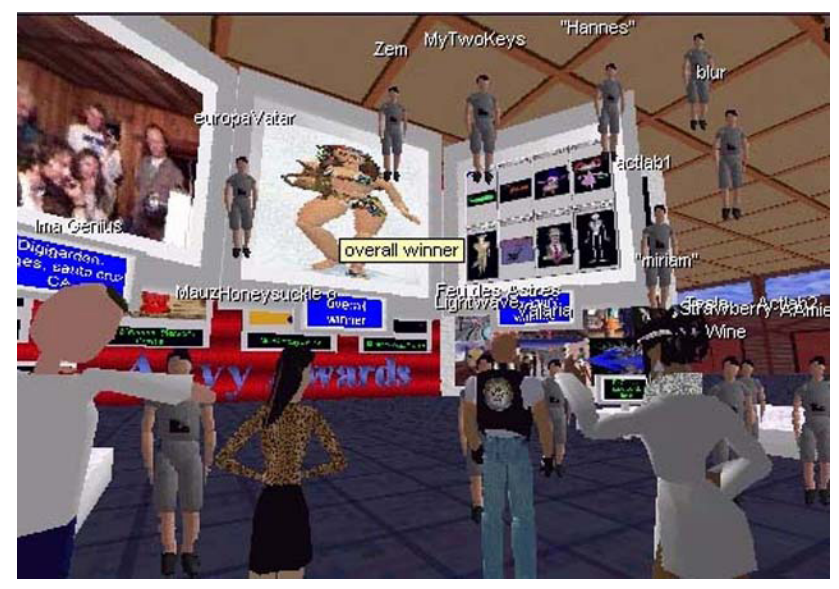

Figure 17. "Avatars98" Avvy Awards ceremony, the Grande Finale. 

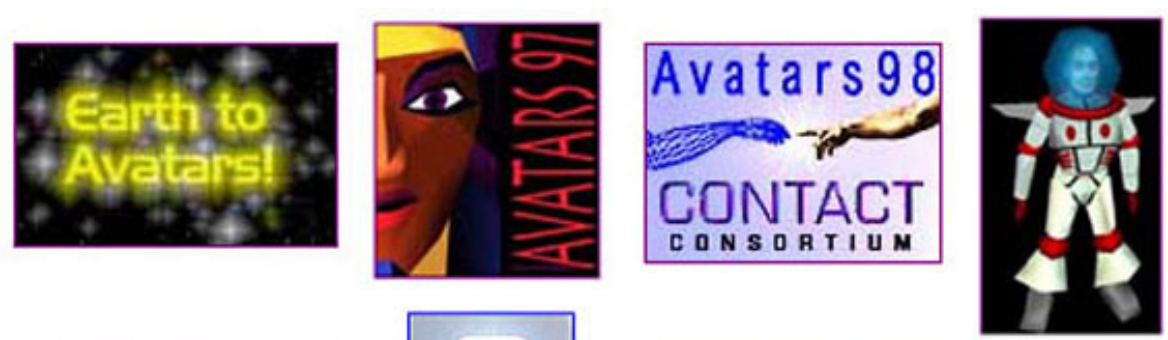

Figure 18. Badges from all eight Avatars conferences (six being held online as Cyberconferences).
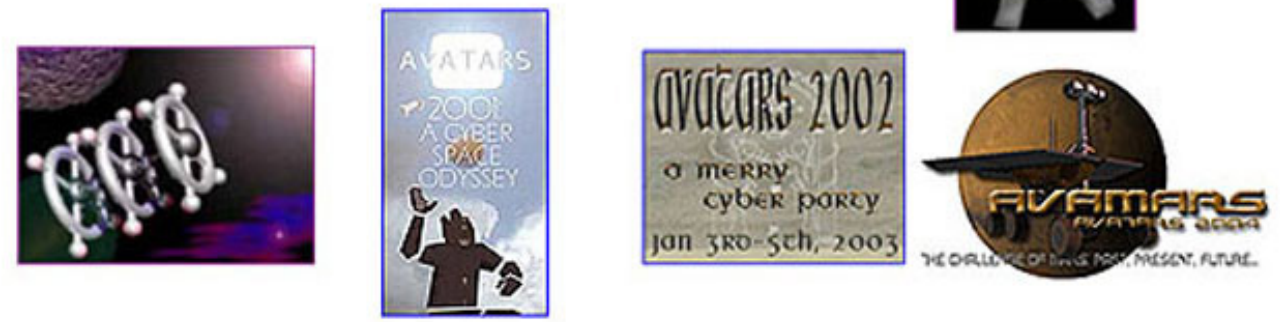

facility to reach beyond the two dozen or so closest users' avatars that could be rendered at a time. Taking cues from theme parks like Disneyland, we had built a series of clear walking paths and quicker "warpers" which would carry users away from the entry area to the four sectors, to help distribute the population and reduce crowding. Wandering the exhibit hall, users would be greeted by staff manning individual booths. Artists were well represented in the Out of this World Art Gallery. A key activity was to attend talks.

Talks were presented in areas called "pods" that were "sound isolated" from the main conference area by being located at specific distances from the main conference area. In Figure 15 we can see Margaret Corbit of the Cornell Theory Center, presenting a session about her projects in the Vlearn3D inaugural track on educational uses of virtual worlds. Each pod was built and configured automatically for each presenter by web database from pre-set assets such as slide images, text, and an audio microphone to tie in live voice through the Hearme online service. Linking eight hours and six tracks of talks together was the "big board" interface, a giant navigable program guide that with a single click would "warp" users' avatars to the appropriate pods throughout the hall (Figure 16).

The two prior in-person conferences had concluded with a "come as your favorite avatar" costume party, which featured a stage show where the best avatars of the year in a number of categories were shown and selected. Bringing this event in-world allowed us to distribute judging and to create a "people's choice" award managed by a vote-bot. The scene in Figure 17 is from the 1998 Avvy Awards at the moment the overall winner was presented onscreen; in this case she was "Summer" - an avatar clothed only in butterflies. Note that only the twodozen closest users' avatars are shown; there were over 450 people present at the ceremony.

Avatars98 had its moments when users complained of very slow object loading and "jerky" performance as their local area was overloaded with avatars and other content. However, throughout the entire event not a single problem occurred with the server and we ran our computers nonstop for 20 hours, capturing chat logs and helping to run the event with volunteers spread around the world. There were a number of stories in the press about "Avatars98" including coverage in Wired News and other magazines and a number of academic journals. By our estimates tracking the number of unique entries, "Avatars98" served several thousand visitors and provided a new benchmark for what a user-built large-scale event could achieve in virtual world cyberspace. We had come a long way from the modest Talking Circle in Sherwood Forest Towne two and a half years earlier and hoped this would help future generations create fun, educational, and well structured in-world events in the future. Other events of note held during this time frame included "TheU Virtual University" (Gold, 1997), an architecture competition in virtual space, "A Virtual Walk on the Moon with Apollo Astronaut Russell Schweickart" (Damer, 1999a) and “Virtual gathering with Terence McKenna” (Damer, 1999b).

\section{THE YEARS OF THE AVATARS CYBERCONFERENCES: 1999-2004}

Based on our positive experience with "Avatars98", the Consortium decided to iterate the experience and produced half a dozen subsequent annual Avatars cyberconferences (Figure 18). Each had a different theme and we experimented with many different layouts of virtual space, from a complex of 
interconnected domes (Figure 19), to a space station (Figure 20), to scenes from a popular film (Figure 21) and book (Figure 22).

\section{The "Burning Man of Bits"}

Ultimately the Avatars events were described as a kind of "Burning Man of Bits" (in reference to the annual user-built arts festival in the Nevada desert). Like Burning Man, Avatars were constructed from the bottom up by users, based on a plan to a yearly theme, and then carried on as a festival of many parallel events, concluding with a "grand finale" event. The Avatars events had shown that the medium of user-built, socially inhabited virtual worlds could have life as large-scale event and performance spaces. That life was to return as a defining feature of virtual worlds in the early twenty-first century.

\section{The "winter of virtual worlds" and their second coming}

The companies and investors who bankrolled the early adopter phase of Internet social virtual worlds ran out of cash and patience by the end of the 1990s

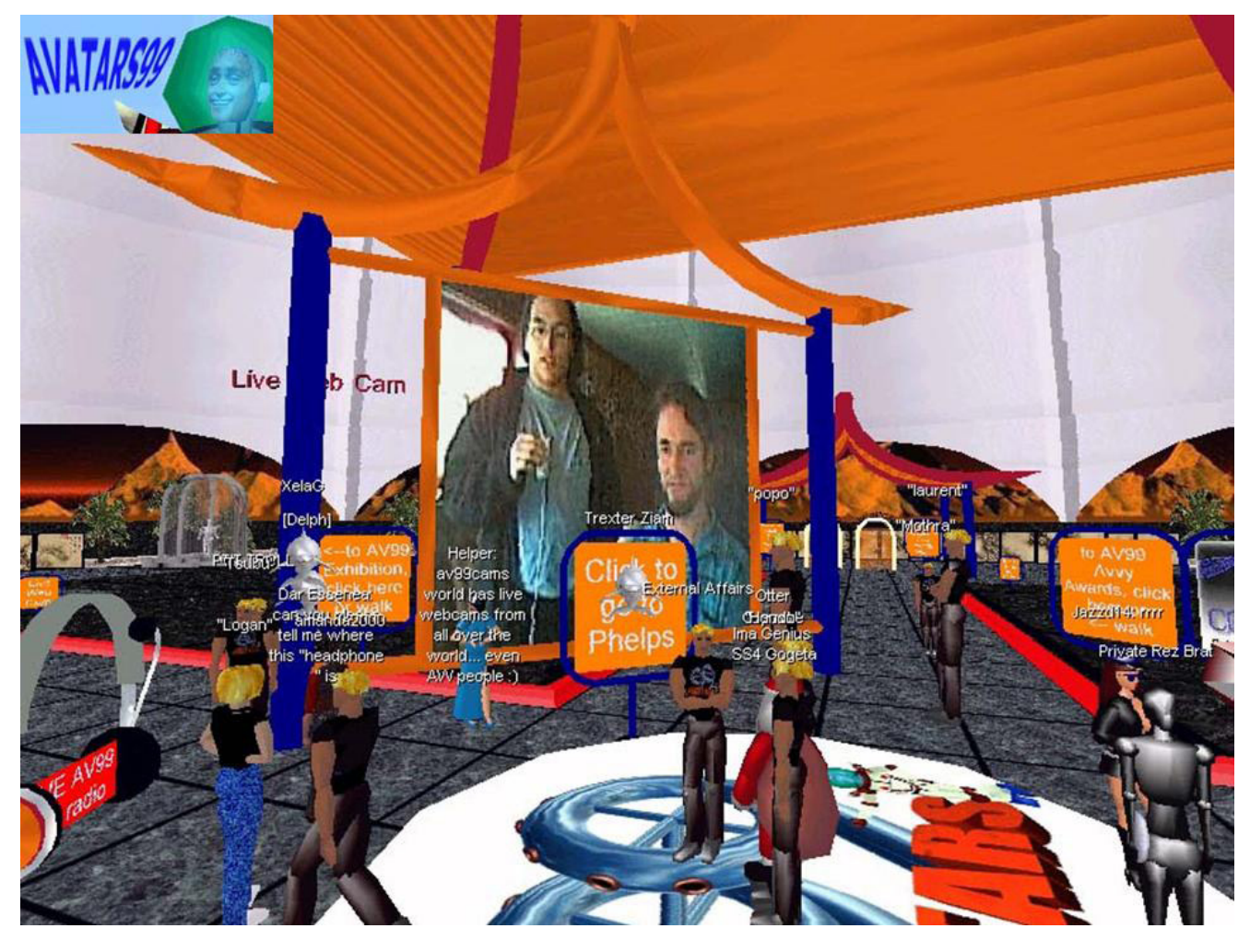

Figures 19 and 20. The spectacular settings of two other Avatars cyber-conferences: avatar attendees journey through connected "millennium domes" in "Avatars99", and a surprise ending to "Avatars 2000" happens when the space station which held the conference was destroyed, casting attendees through a "wormhole".

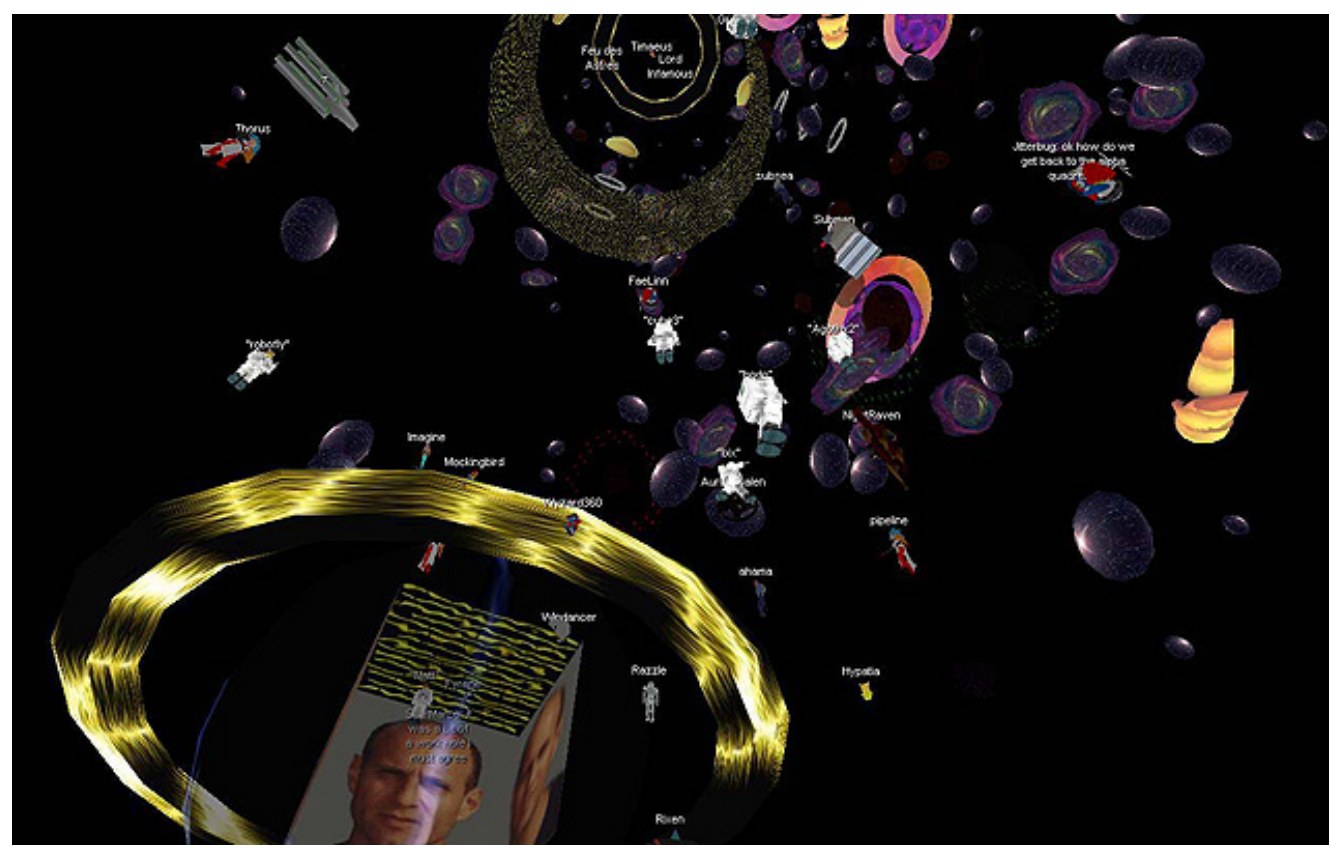




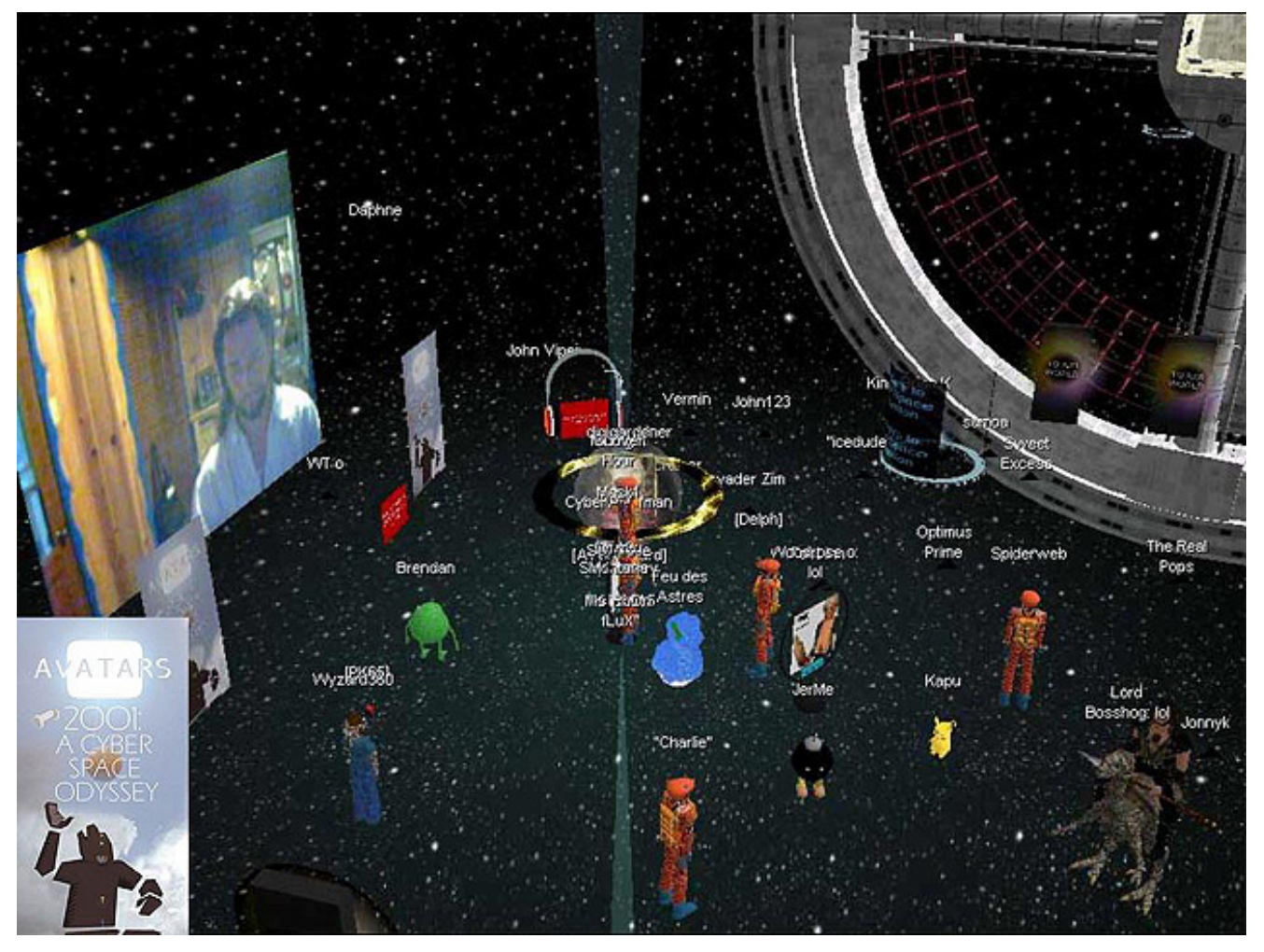

Figures 21 and 22. The opening space in "Avatars 2001, a Cyberspace Odyssey", is a parody of Stanley Kubrick's film 2001 A

Space Odyssey and "Avatars 2002" brings a book to life in a reconstruction of Middle Earth from JRR Tolkien's Lord of the Rings.

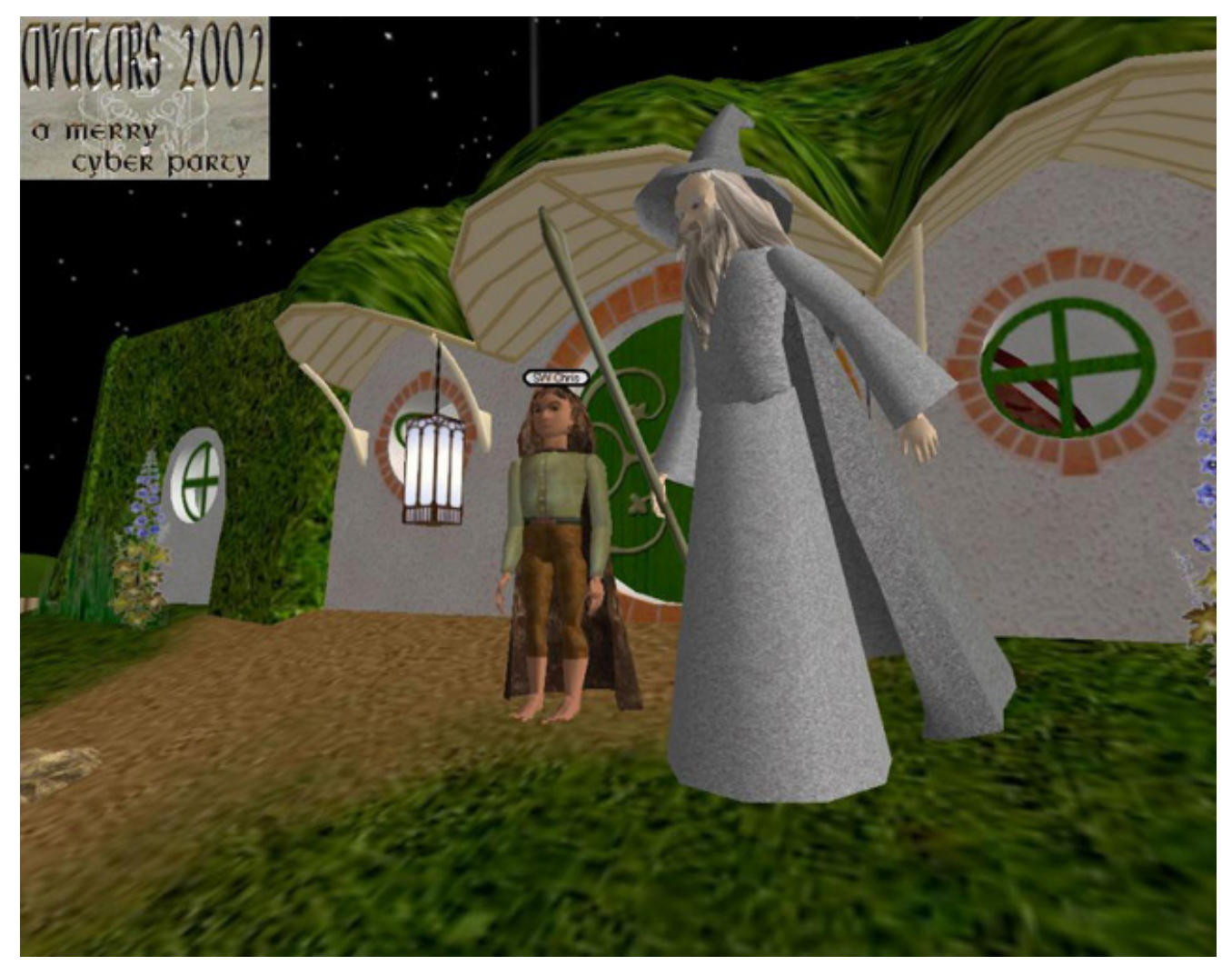

and most firms changed hands or vanished, even before the "dotcom crash" of 2000. Only the original Alphaworld, which became Active Worlds, survived relatively intact. A "winter" period followed during which it was unclear whether social virtual worlds were a viable medium or an evolutionary dead-end.
The Avatars cyber-conferences came to an end in 2003 and it felt like "the party was over" for the exciting early adopter phase of the medium.

At about this time, the rise of social networking software (Friendster, MySpace, Facebook, Orkut, Tribe.net, LinkedIn), texting and graphics on mobile devices (SMS, DoCoMo, Cyworld), voice and video 


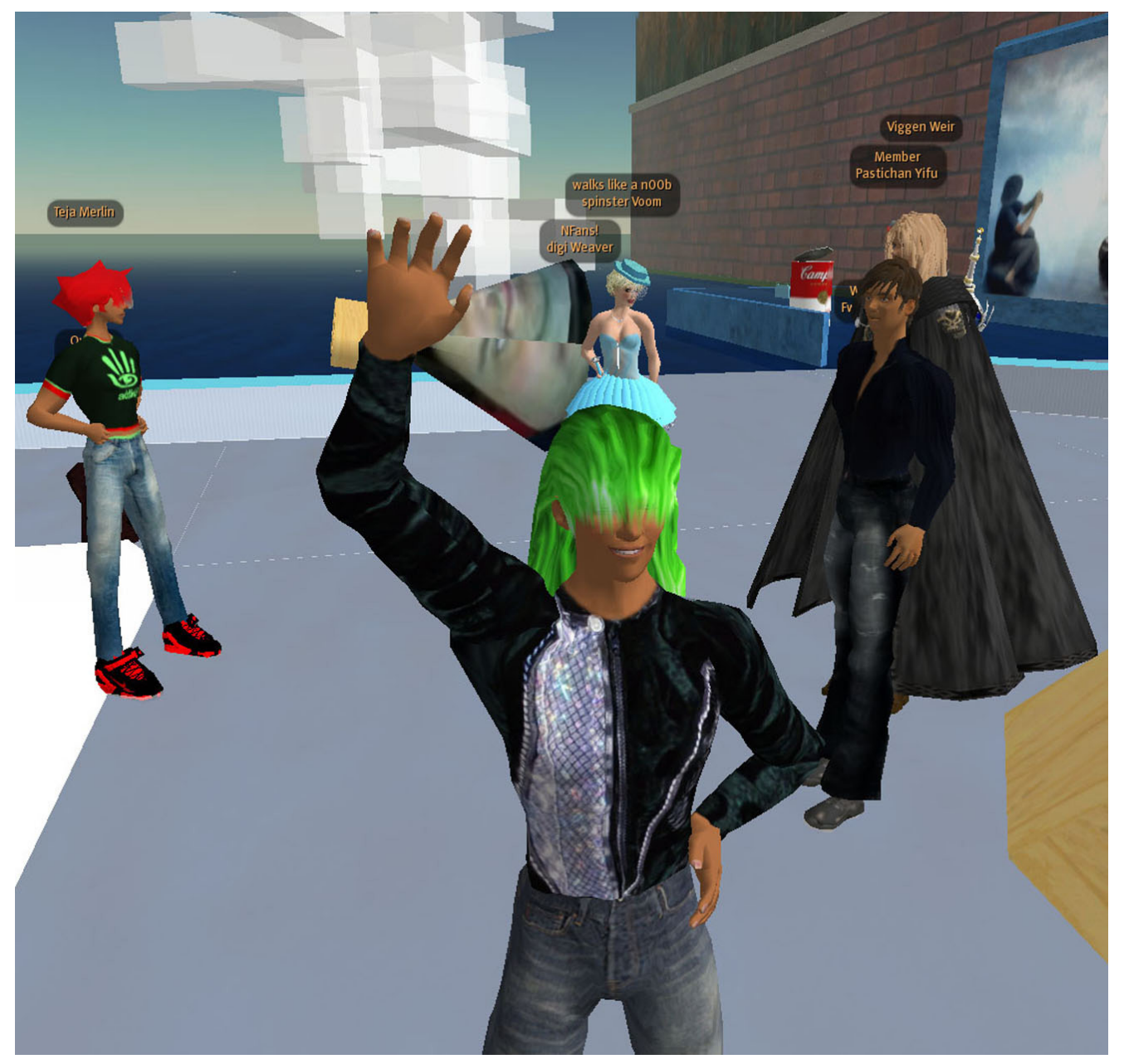

Figure 23. The author greets you wearing an avatar garment of his own design in Second Life, May 2007.

over IP (Skype, YouTube) and collective literary constructions (Wikipedia) created a whole new awareness and acceptance of multiple forms of identity online. In parallel, the great success of "massively multi player online games" from Everquest (1999) to today's World of Warcraft was a financial driver for vastly better 3D graphics hardware and network infrastructure, including consumer broadband.

\section{The show must go on}

Incubating within this winter period were firms like Linden Lab (creator of Second Life), and There, Inc (creator of the virtual world There), which emerged to re-energize the social virtual world space.

Second Life and There each launched a public beta in early 2003. Second Life built on two key concepts from the first-generation virtual world platforms of the 1990s: the user-empowering in-world building techniques of Alphaworld and the object economy of Habitat/WorldsAway that created a marketplace of objects (bought and sold in a currency called Linden Dollars). Thus there emerged a large community of object makers, builders, and marketers.
A fascinating extension to the object economy was the ability of users to clothe avatars in configurable animated garments (Figure 23), creating a fashion industry that attracted a whole new clientele. In Second Life, virtual land was purchased and rent is due, much like a web-hosting service, ensuring that spaces stayed actively maintained and that Linden Lab secured a revenue stream.

Today, with the second coming of the avatar and social virtual worlds medium, predictably it is meetings and larger events from interviews on stage to fashion shows that are a driving force behind the growth and attraction to life in-world (Figure 24). The energetic Second Life user community has started organizing large physical gatherings to complement their lives in-world, in an echo of the original 1996 Earth to Avatars conference.

\section{LOOKING BACK TO LOOK FORWARD}

A surprising property of almost any newly emerged technology is how rapidly the basic form emerges and how tenaciously it dominates. The basic plan for the automobile was in place by 1900 , the format 

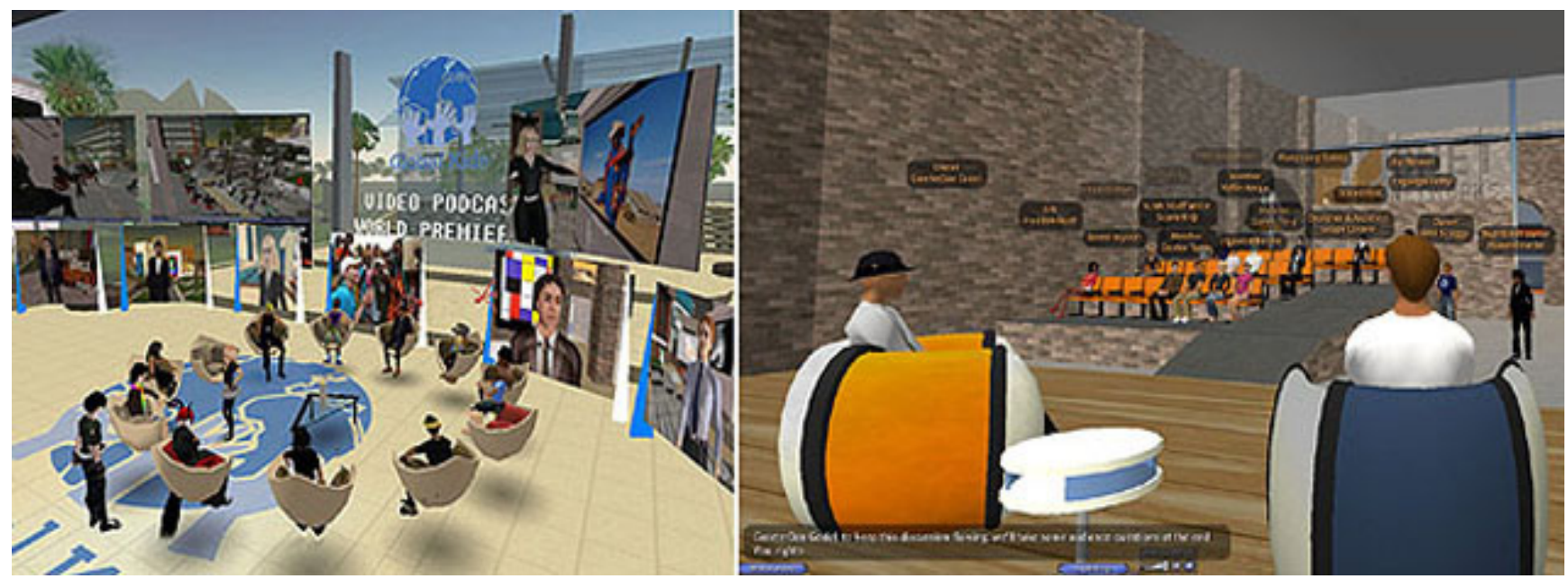

Figure 24. Meetings in Second Life today, showing a kind of Talking Circle as well as an auditorium for interviews; events in Second Life continue to grow in size and scope today.

for TV shows and commercials was set by the late 1940 s, personal computing and even networked interaction was all sewn up as an invention by about 1977 , and, the virtual world, it seems, had all the properties, features, and uses in place by about 1998 (or, Habitat users might argue, by 1986). Comparing a session at the Avatars98 cyberconference with any gathering in Second Life today, there are actually no significant new affordances, no new tricks or patterns of behavior that I personally can find. The layout of spaces and how users interact within them is amazingly stable from even the first experimental meeting spaces back in Sherwood Forest Towne in the Spring of 1996. This is no difference on the game-play side of things as in 1974 Maze War established all the conventions of a first-person shooter game that were then re-invented in Doom 20 years later (and they have not changed since).

So what does this tell us about the future of the virtual worlds medium? Probably that, just like any other new technology, early visionaries, promoters, and business people will always overreach the actual practical and sensible limits of what it can deliver, and then the medium will settle down to occupy a niche, competing for attention and investment dollars with other related modes of interaction. Do I see virtual worlds becoming the office worker's preferred medium of daily interaction? This has been foretold for more than a decade and has never gone beyond early adopter trials. Webex, Skype, and other simple collaborative tools will be a hard market share to penetrate, even with virtual worlds' purported advantages. Immersive VR settled down into narrow but sustaining niches in training, telemedicine, and the treatment of certain disorders such as phobias, but failed to become an all-encompassing widely used medium for interaction and entertainment. Virtual worlds have gone on to establish a much wider audience but are still currently limited to a few vertical applications with a relatively small user audience. There are no large walkable 3D shopping malls as predicted, as people prefer to surf the much easier 2D web malls akin to the earlier paper catalogue. People also do not yet flock to virtual worlds in large numbers to hear a famous band jamming or attend a major art opening. This may yet come as the technology scales, however.

What I believe to be the "killer app" of virtual worlds is something right in front of us, seen every day from last century's ancient landscapes of Alphaworld to last night's sexier spaces of Second Life ... that, is the presence of a crowd. A crowd attracts attention in the primate mind. A crowd suggests something of importance, an in-group, inside information, or just gossip, a chance to flirt, a lynching, or perhaps just an opportunity to escape the boredom of non in-world life for just a moment. A structured crowd in a designed space might suggest the presence of a leader, an orator or other performer, a worldmaker, a troublemaker, or an old-fashioned showoff. In any of these cases a crowd is almost irresistibly attractive.

So perhaps it is really all just about meeting in the ether.

\section{POSTAMBLE}

From just a dozen years ago when may of us wondered if the avatar medium would survive I personally find myself delighted that, today, avatars and their worlds are propagating everywhere. You can journey through Second Life, There, and many 
other grid-enabled "big worlds" to IMVU's small and intimate 3D instant-message-themed avatar rooms, to web-embedded worlds like Google's Lively (unfortunately recently discontinued) and Vivaty to social enclaves appearing on game consoles where users interact and create personalized home worlds for use while outside game play. Virtual worlds are now blending with Web 2.0 social networks such as Facebook and some kind of magical convergences always seems just around the corner. Mobile phones are now scaling the performance and pixel density curve and will soon host rich social virtual worlds, perhaps using the lip-synching voice avatar heads pioneered by Onlive Traveler. These devices are connected to GPS and may ultimately yield a mixed-reality view of the virtual and physical worlds. So, if we imagine just a few years into the future, searching for friends in a New Year's Eve crowd in Times Square in 2012, you might simply peer into your personal virtual-worlds-capable device and there, in the milling parallel reality crowd of avatars, would be everyone physically present from your social network.

\section{REFERENCES}

Damer, B. F. (1996a). Earth to avatars - contact, culture and community in digital space. Available at http://www.ccon. org/events/conf96.html

Damer, B. F. (1996b). Garden party event in Sherwood Forest. Available at http://www.ccon.org/events/mixalpha.html

Damer, B. F. (1997a). Avatars! Exploring and building virtual worlds on the internet. Berkeley: Peach Pit Press.

Damer, B. F. (1997b). Avatars 97 - the human race in cyberspace. Available at http://www.ccon.org/conf97/ index.html

Damer, B. F. (1999a). A virtual walk on the moon with Apollo Astronaut Russell Schweickart. Available at http://www. digitalspace.com/worlds/apollo/jul20event.html

Damer, B. F., \& Gold, S.G. (1997c). Sherwood Forest Towne. Available at http://www.ccon.org/events/sherwood.html

Damer, B. F., \& Gold, S.G. (1998). Avatars 98 and the other Avatars cyber-conferences through 2003. Available at http://www.ccon.org/events/index.html

Damer, B. F., \& Thompson, G. (2004). Maze War 30 year retrospective - Digibarn Computer Museum. Available at http://www.digibarn.com/history/04-VCF7-MazeWar/index. html

Damer, B. F., McKenna, T., \& McKenna, F. (1999b). Virtual gathering with Terence McKenna. Available at http://www. digitalspace.com/worlds/fan-terencem/index.html

Gold, S. G. (1997). TheU Virtual University \& Architecture Competition. Available at http://www.ccon.org/theu/index. html
Morningstar, C., \& Farmer, R. (1991). The lessons of Lucasfilm's Habitat. Available at http://www.fudco.com/chip/ lessons.html [also published in Benedikt, M. (Ed.). (1991). Cyberspace: First steps. Cambridge, MA: MIT Press].

Stephenson, N. (1992). Snow crash. New York: Bantam Books.

\section{FURTHER READING}

DigitalSpace and Contact Consortium publications on virtual worlds, 1995-2007. Available at http:// www.digitalspace.com/papers/

Virtual Worlds Timeline history project. Available at http://www.vwtimeline.org. This project chronicles the origins, evolution and current trends in the virtual worlds medium, from its beginning in the 1970s through the early adopter phase of the Internet-based environments of the 1990s to the mainstream platforms of the 2000 s. The project is supported by the Contact Consortium, DigitalSpace, multiple academic partners including Umea University in Sweden, Stanford University in the USA and the Web History Project.

\section{CORRESPONDENCE}

Bruce Damer, DigitalSpace, 343 Soquel Ave, Suite 70, Santa Cruz, CA 95063, USA.

Email: bdamer@digitalspace.com

ISSN 1749-3463 print/ ISSN 1749-3471

DOI: 10.1080/17493460903020877

(C) Artifact 2008 